Article

\title{
Recombinant Expression and Stapling of a Novel Long-Acting GLP-1R Peptide Agonist
}

\author{
Sam Lear®, Hyosuk Seo, Candy Lee, Lei Lei, Zaid Amso®, David Huang, Huafei Zou, \\ Zhihong Zhou, Vân T. B. Nguyen-Tran and Weijun Shen *
}

The Scripps Research Institute, d/b/a Calibr, a division of Scripps Research, 11119 North Torrey Pines Road, Suite 100, La Jolla, CA 92037, USA; samlear@scripps.edu (S.L.); hyseo@scripps.edu (H.S.); candylee@scripps.edu (C.L.); leilei@scripps.edu (L.L.); zaidamso@scripps.edu (Z.A.); dhuang@scripps.edu (D.H.); zouhuafei@gmail.com (H.Z.); zhouzhihong0818@yahoo.com.sg (Z.Z.); vnguyent@scripps.edu (V.T.B.N.-T.)

* Correspondence: wshen@scripps.edu

Academic Editor: Elio Pizzo

Received: 24 April 2020; Accepted: 12 May 2020; Published: 28 May 2020

\begin{abstract}
Owing to their pleiotropic metabolic benefits, glucagon-like peptide-1 receptor (GLP-1R) agonists have been successfully utilized for treating metabolic diseases, such as type 2 diabetes and obesity. As part of our efforts in developing long-acting peptide therapeutics, we have previously reported a peptide engineering strategy that combines peptide side chain stapling with covalent integration of a serum protein-binding motif in a single step. Herein, we have used this strategy to develop a second generation extendin- 4 analog rigidified with a symmetrical staple, which exhibits an excellent in vivo efficacy in an animal model of diabetes and obesity. To simplify the scale-up manufacturing of the lead GLP-1R agonist, a semisynthesis protocol was successfully developed, which involves recombinant expression of the linear peptide followed by attachment of a polyethylene glycol (PEG)-fatty acid staple in a subsequent chemical reaction step.
\end{abstract}

Keywords: diabetes; obesity; stapled peptide; recombinant expression; lipidation; semisynthesis; long-acting; PEG; GLP-1R agonist; exenatide

\section{Introduction}

Glucagon-like peptide-1 receptor (GLP-1R) agonists have attained blockbuster status as therapeutics in the area of metabolic diseases. In preclinical and clinical studies, GLP-1R agonists have been shown to lower fasting plasma glucose and promote glycemic control through glucose-dependent insulinotropic and glucagonostatic effects, without conferring risks of hypoglycemia [1,2]. The incretin effect resulting from targeting GLP-1R led to the successful commercialization of three short-acting agonists [exenatide, lixisenatide, and liraglutide] and three long-acting agonists [bydureon, dulaglutide, and semaglutide] as therapeutics for type 2 diabetes (T2D) [3]. In addition to the above metabolic outcomes, GLP-1R agonists are able to induce sustained weight loss through appetite suppression and delayed gastric emptying, ultimately leading to the commercialization of the once daily liraglutide for chronic weight management in patients with obesity [4]. More recently, GLP-1R agonists have also shown promise in the clinical studies for management of nonalcoholic steatohepatitis, a liver disease with no approved therapies to date $[5,6]$.

As part of our efforts in developing long-acting therapies for chronic diseases, we have previously utilized the in-house developed polyethylene glycol (PEG)-fatty acid stapling technology to produce "E6", a potent, long-acting GLP-1R agonist exhibiting excellent efficacy in animal models of diabetes and obesity [7]. Despite the superior pharmacokinetic properties, the first-generation staples used to synthesize E6 were found to produce mixtures of regioisomers during the stapling reaction. While 
this did not affect the activity of the resulting conjugates, it was undesirable as chemical heterogeneity presents challenges during manufacturing and pharmacological and toxicological characterizing of the isomeric products. Herein, we report the use of an improved, structurally symmetric staple, which circumvents the above problems by producing only one product upon stapling. Moreover, the methionine residue present in E6 was replaced with leucine to mitigate instability due to oxidation. The lead candidate demonstrates similarly long half-life and excellent in vivo efficacy in controlling blood glucose in mice. In addition, we report the semisynthesis of the lead GLP-1R agonist involving expression of the linear peptide functionalized with chemically reactive cysteine residues, followed by attachment of a PEG-fatty acid staple in a subsequent chemical reaction step. This protocol can be used to prepare large quantity of the target GLP-1R agonist with high purity for clinical testing and subsequent commercialization as a therapeutic for T2D and obesity.

\section{Results and Discussion}

Lipidation is an established approach for half-life extension of therapeutic peptides, and has found prominence in the metabolic disease space, where many lipidated peptides and proteins such as GLP-1R agonists (semaglutide [8], liraglutide [9]) and insulin analogs (insulin detemir [10] and degludec [11]) have been approved as therapies for diabetes and obesity. Furthermore, peptide stapling is a technique that can be used to improve the potency and serum stability of bioactive peptides, which shows promise in clinical peptide drug development [12,13]. Previously, we developed a long-acting exenatide (Ex-4) analog stapled at engineered Cys positions within the sequence, incorporating an optimized lipid moiety for enhanced serum protein binding [3,7]. The peptide, Ex-4[E17C, E24C]-S1 ("E6"), demonstrated significantly improved half-life and in vivo efficacy in chronic obesity models, including enhanced glucose control and body weight reduction. Despite being a promising lead compound, we sought to address the structural asymmetry of the $\mathbf{S 1}$ staple (Figure 1), which renders it susceptible to the formation of regioisomers upon stapling of the diCys-containing precursor peptide. This required the development of a symmetric analog of the staple (S2, Figure 1), which cannot form regioisomers and which we have used recently to generate long-acting oxyntomodulin analogs [14].<smiles>[Y6]SCC(=O)NCCC[C@H]([R])NC(=O)CS[Na]</smiles>

S1<smiles>[R]CCC(=O)N(CCNC(=O)CSCCS)CCSCCS</smiles>

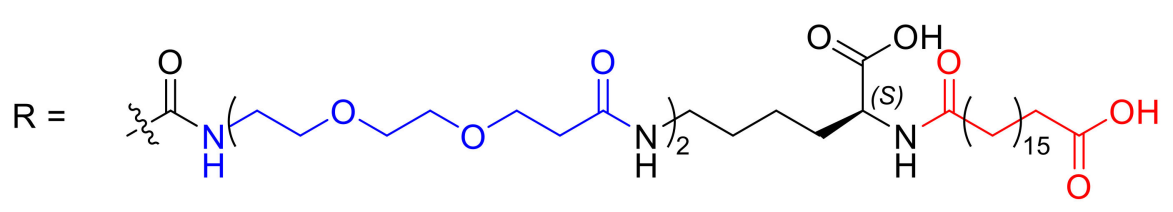

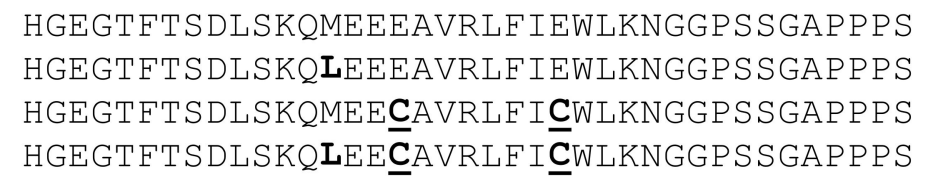

Figure 1. Structures of lipidated moieties, S1 and S2, used for stapling, and exenatide (Ex-4) analog sequences. 


\subsection{In Vitro Activity and Pharmacokinetics of Symmetric Staple Analog}

Synthesis of staple S2 and the Ex-4[E17C, E24C] sequence, and stapling of the synthetic peptide were carried out as previously reported [3,14]. In vitro receptor activity of synthetic Ex-4[E17C, E24C]-S2 was evaluated in mammalian cell lines overexpressing GLP-1R, either via direct readout of intracellular cyclic adenosine monophosphate (cAMP) release, or through a cAMP response element luciferase reporter (CRE luc), and compared with commercial GLP-1R agonist semaglutide (Figure 2 and Table 1). Both S1- and S2-stapled analogs exhibit similar activity to the native Ex-4 control and semaglutide.

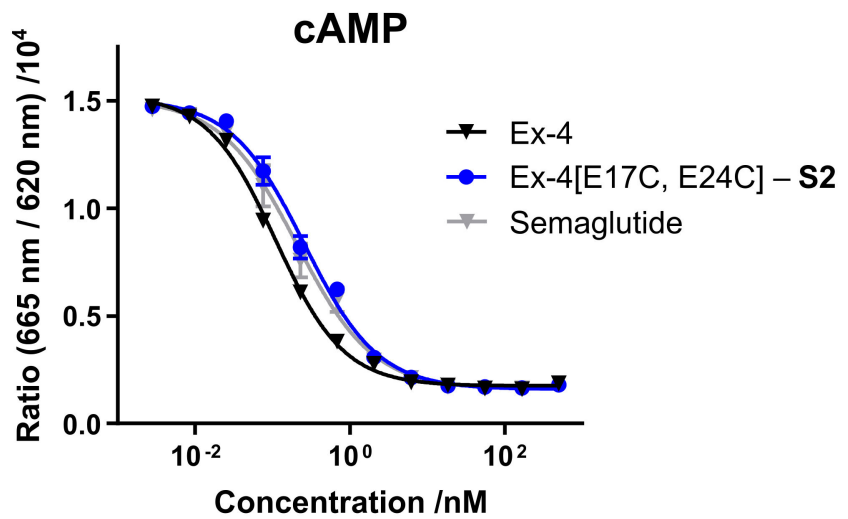

Figure 2. Dose-response curves for glucagon-like peptide-1 receptor (GLP-1R) agonists in intracellular cyclic adenosine monophosphate (cAMP) assay (EC 50 values shown in Table 1).

Table 1. Activity of chemically-synthesized GLP-1R agonist sequences stapled with S1 or S2 (cAMP responsive element (CRE) luciferase reporter assay and intracellular cAMP assay, see Materials and Methods section).

\begin{tabular}{lccc}
\hline \multirow{2}{*}{ Peptide } & Staple & \multicolumn{2}{c}{ GLP-1R EC $\mathbf{5 0} / \mathbf{p M}$} \\
\cline { 3 - 4 } & & CRE & cAMP \\
\hline Ex-4 & - & $37 \pm 3$ & $111 \pm 6$ \\
Ex-4[E17C, E24C] & S1 & $39 \pm 3$ & - \\
Ex-4[E17C, E24C] & S2 & - & $260 \pm 20$ \\
Semaglutide & - & $24 \pm 2$ & $210 \pm 20$ \\
\hline
\end{tabular}

Next, we sought to assess the half-life of Ex-4[E17C, E24C]-S2 in mouse. Male CD-1 mice $(n=4)$ were administered peptide via either SC or IV route at $0.12 \mathrm{mg} / \mathrm{kg}$, and plasma samples were collected at $0.25,1,3,7,24,48$, and $72 \mathrm{~h}$ for SC and $5 \mathrm{~min}$ and 1, 3, 7, 24, 48, and $72 \mathrm{~h}$ for IV dosing. Peptide plasma concentrations were determined via the CRE luciferase reporter assay, as described. Pharmacokinetic data are given in Figure 3 and Table 2. Ex-4[E17C, E24C]-S2 exhibits a half-life of over 7 and 9 h via SC and IV administration, respectively, which is comparable to that previously reported for the S1 analog and semaglutide (data not shown) [7].

Table 2. Mouse pharmacokinetic data for Ex-4[E17C, E24C]-S2.

\begin{tabular}{llcc}
\hline & Parameter & IV & SC \\
\hline Dose & $/ \mathrm{mg} \cdot \mathrm{kg}^{-1}$ & 0.12 & 0.12 \\
$\mathrm{~T}_{1 / 2}$ & $/ \mathrm{h}$ & $9 \pm 1$ & $7.4 \pm 0.4$ \\
$\mathrm{CL}$ & $/ \mathrm{mL} \cdot \mathrm{min}^{-1} \cdot \mathrm{kg}^{-1}$ & $0.24 \pm 0.04$ & $0.22 \pm 0.05$ \\
$\mathrm{~T}_{\max }$ & $/ \mathrm{h}$ & $0.08 \pm 0$ & $3 \pm 0$ \\
$\mathrm{C}_{\max }$ & $/ \mu \mathrm{hg} \cdot \mathrm{mL}^{-1}$ & $1.2 \pm 0.2$ & $0.7 \pm 0.2$ \\
$\mathrm{AUC}_{\text {all }}$ & $/ \mathrm{h} \cdot \mathrm{\mu g} \mathrm{mL}^{-1}$ & $8 \pm 1$ & $9 \pm 2$ \\
$\mathrm{~V}_{\mathrm{z}}$ & $/ \mathrm{L} \cdot \mathrm{kg}^{-1}$ & $0.20 \pm 0.06$ & $0.14 \pm 0.04$ \\
\hline
\end{tabular}




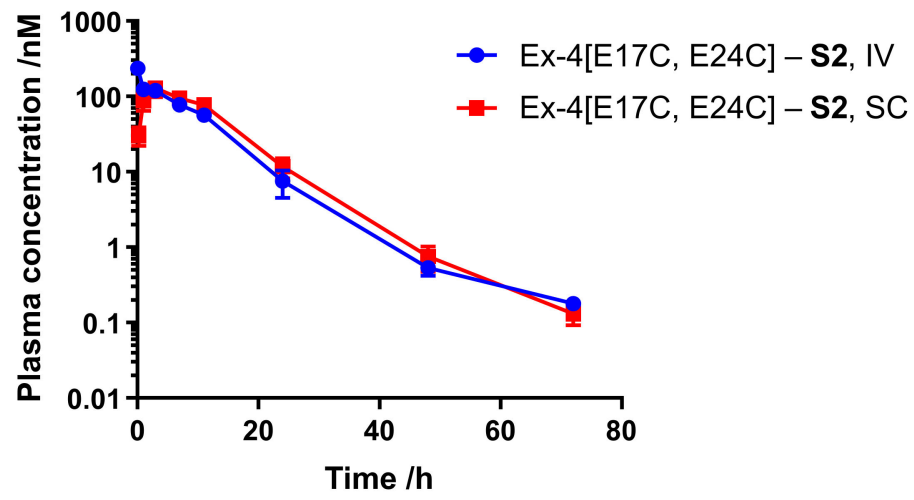

Figure 3. Mouse pharmacokinetic profiles for Ex-4[E17C, E24C]-S2. Peptides were administered via intravenous (IV) or subcutaneous (SC) injection to male CD-1 mice $(\mathrm{n}=4)$ at $0.12 \mathrm{mg} / \mathrm{kg}$. Blood samples were collected between 0.25 and $72 \mathrm{~h}$ after dosing, and plasma concentration of the peptides was analyzed via CRE luc reporter functional assay, as detailed in the Materials and Methods section.

\subsection{In Vivo Efficacy of Symmetric Staple Analog}

Given the confirmed in vitro activity and mouse half-life demonstrated for symmetric staple analog Ex-4[E17C, E24C]-S2, the next step was to fully validate efficacy of the new lead peptide in a chronic in vivo diet-induced obesity (DIO) model. Peptide was administered daily to diet-induced obese mice for 12 days, at either 0.04 or $0.12 \mathrm{mg} / \mathrm{kg}$ via SC injection, alongside semaglutide $(0.04 \mathrm{mg} / \mathrm{kg})$ and vehicle control (Figure 4). Ex-4[E17C, E24C]-S2 exhibited dose-dependent reduction in food intake (Figure $4 \mathrm{a}$ ) and body weight (Figure $4 \mathrm{~b}$ ), and comparable efficacy to semaglutide at $0.04 \mathrm{mg} / \mathrm{kg}$ in food intake and body weight reduction, glucose control in the oral glucose tolerance test (OGTT) at day 1 (Figure $4 c, d$ ), and reduction of serum triglycerides (Figure 4e). Furthermore, our peptide showed a superior reduction of total cholesterol (Figure 4f) and liver weight (Figure 4g), despite the relatively short treatment period.

\subsection{Recombinant Expression and Stapling of M14L Variant}

Next, a robust method for expression of the linear diCys-functionalized Ex-4[E17C, E24C] peptide needed to be developed, as an alternative to chemical synthesis. In addition, we sought to address the metabolic liability associated with the presence of a methionine side chain, which is sensitive to oxidation. This was solved by a simple Met-to-Leu substitution, which has previously been validated for exenatide as resulting in no loss of potency against the GLP-1 receptor $[15,16]$. We anticipated that soluble expression would be best suited for the relatively short and highly soluble Ex-4[M14L, E17C, E24C] sequence, and to this end a thioredoxin (Trx) expression system was selected, as shown in Figure $5[17,18]$. A His 6 tag was incorporated to enable purification via immobilized metal affinity chromatography (IMAC) using nickel sepharose resin, with an enterokinase (EK) cleavage site for subsequent removal of the $\mathrm{N}$-terminal tags.

The expression construct was cloned into a pET28a vector and expressed in E. coli as the cytoplasmic, soluble fraction. After culturing overnight at $37^{\circ} \mathrm{C}$ using kanamycin selection, expression was induced at $\mathrm{OD}_{600}=0.8$ and the culture was incubated for $4 \mathrm{~h}$. Following centrifugation, lysis of the cell pellet, and further centrifugation, the supernatant containing soluble fusion was purified using nickel affinity chromatography with elution at $200 \mathrm{mM}$ imidazole to yield $\sim 30 \mathrm{mg} / \mathrm{L}$ of protein. Selective cleavage of the Trx and $\mathrm{His}_{6}$ tags was achieved via enterokinase digestion overnight at room temperature. After concentration the cleaved product, Ex-4[M14L, E17C, E24C], was purified via reversed-phase HPLC (RP-HPLC) to yield $4 \mathrm{mg} / \mathrm{L}$ of peptide. The purified linear peptide was then stapled as previously reported, using dibromoacetyl-S2 in acetonitrile/ammonium bicarbonate buffer ( $\mathrm{pH}$ 8.5) for $4 \mathrm{~h}$, followed by acidification with acetic acid and purification via a second RP-HPLC step. 
(a)

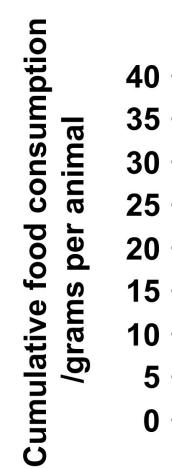

(c)

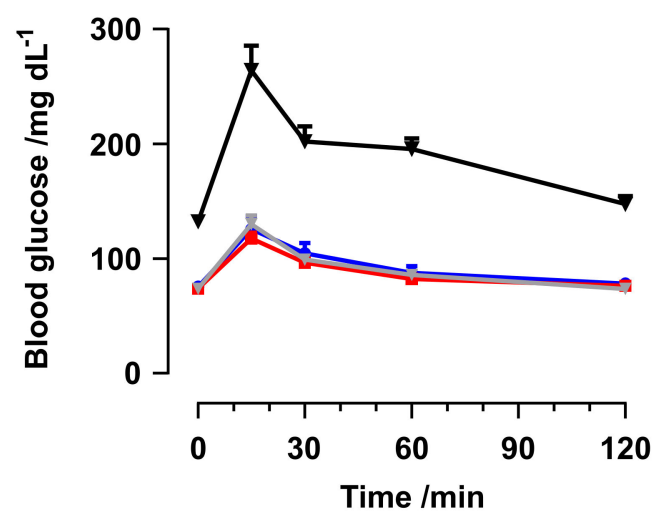

(b)

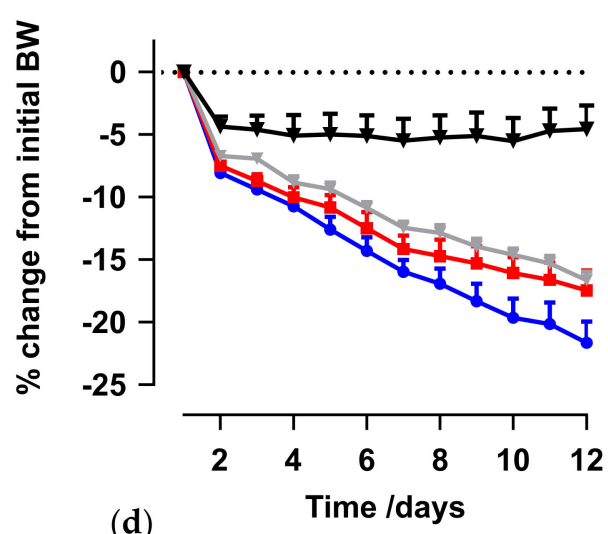

(d)
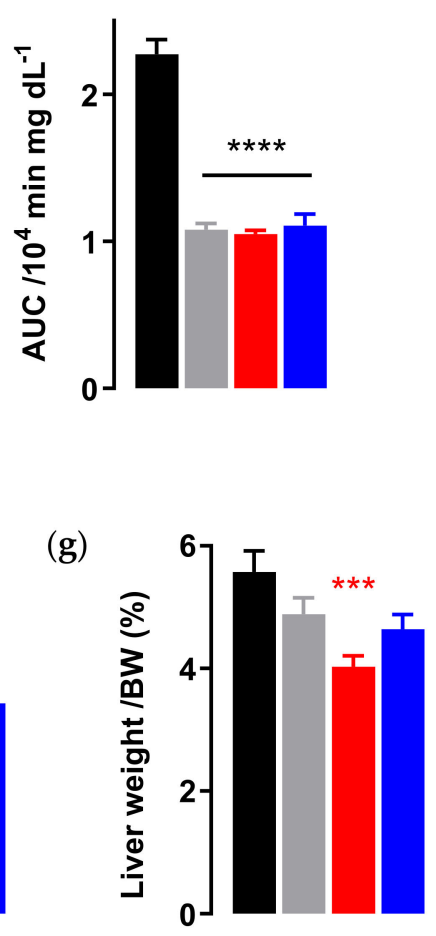

(e)

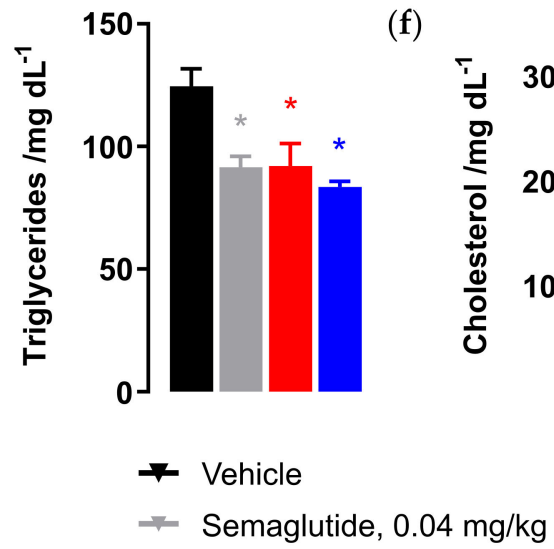

(g)

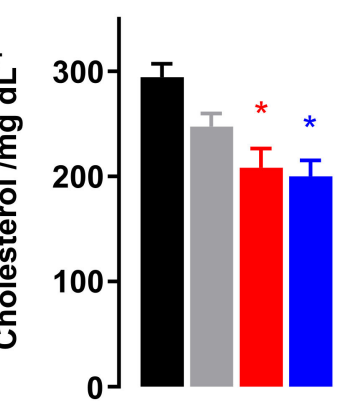

$=$ Ex-4[E17C, E24C] - S2, $0.04 \mathrm{mg} / \mathrm{kg}$

$\rightarrow$ Ex-4[E17C, E24C] - S2, $0.12 \mathrm{mg} / \mathrm{kg}$

Figure 4. Daily SC dosing of peptide or vehicle control (phosphate-buffered saline) in diet-induced obesity (DIO) mouse model over 12 days ( $n=6$ per group), first dose administered on day 1 following overnight fast: (a) cumulative food intake; (b) \% change from initial body weight (BW); (c) oral glucose tolerance test (OGTT) at day 1 with (d) area under the curve (AUC); (e) serum triglycerides, (f) total cholesterol, and (g) liver weight as a percentage of body weight (BW) at day $13 ;{ }^{*} p<0.05,{ }^{* * *} p<0.001$, and ${ }^{* * * *} p<0.0001$, relative to vehicle control. 


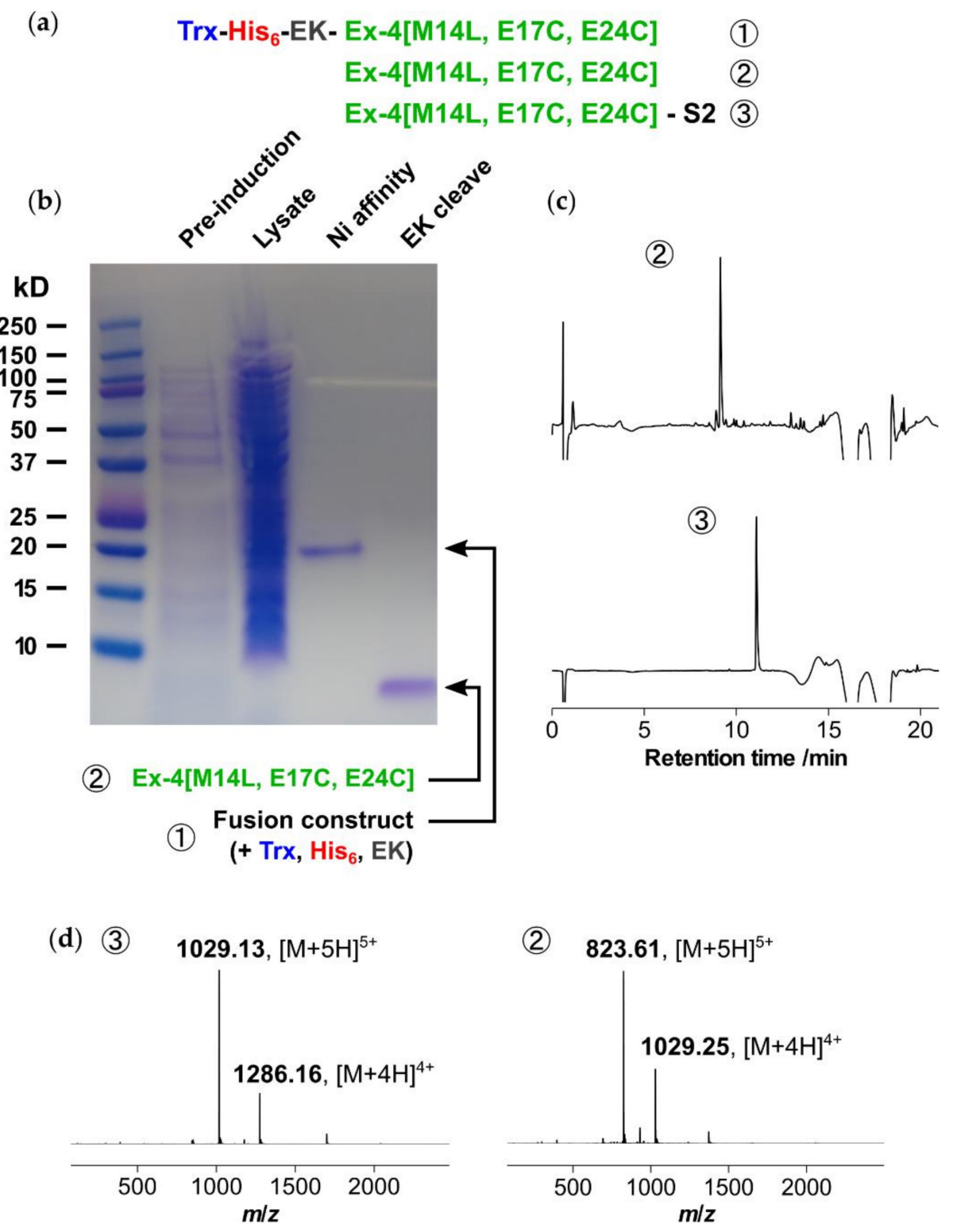

Figure 5. Expression in E. coli, characterization and stapling of Ex-4[M14L, E17C, E24C] with S2: (a) fusion construct for expression, incorporating thioredoxin (Trx) expression tag, $\mathrm{His}_{6}$ tag for purification and enterokinase (EK) cleavage site; (b) sodium dodecyl sulfate-polyacrylamide gel electrophoresis (SDS-PAGE) showing supernatant following cell lysis, material after Ni affinity purification and subsequent EK cleavage; (c) UV chromatogram (absorbance at $214 \mathrm{~nm}$ ) of recombinantly expressed peptide (2) (86\% purity), and peptide following stapling and reversed-phase HPLC (RP-HPLC) purification, (3) (96\% purity); (d) electrospray ionization mass spectrometry (ESI-MS) characterization of (2) and (3) (calculated $m / z$ : (2) 823.81 and (3) $1028.93[\mathrm{M}+5 \mathrm{H}]^{5+}$, (2) 1029.51 , and (3) $1285.92[\mathrm{M}+4 \mathrm{H}]^{4+}$ ).

\subsection{Activity, Pharmacokinetics, and in Vivo Efficacy of Semisynthetic M14L Analog}

Activity of semisynthetic Ex-4[M14L, E17C, E24C]-S2 was evaluated using cAMP and CRE luc reporter assays (Figure 6 and Table 3). As expected, the Met-to-Leu analog demonstrates equal or better potency than the native methionine-containing peptide, and the semisynthetic (recombinant) product exhibits comparable activity to the fully synthetic material. 

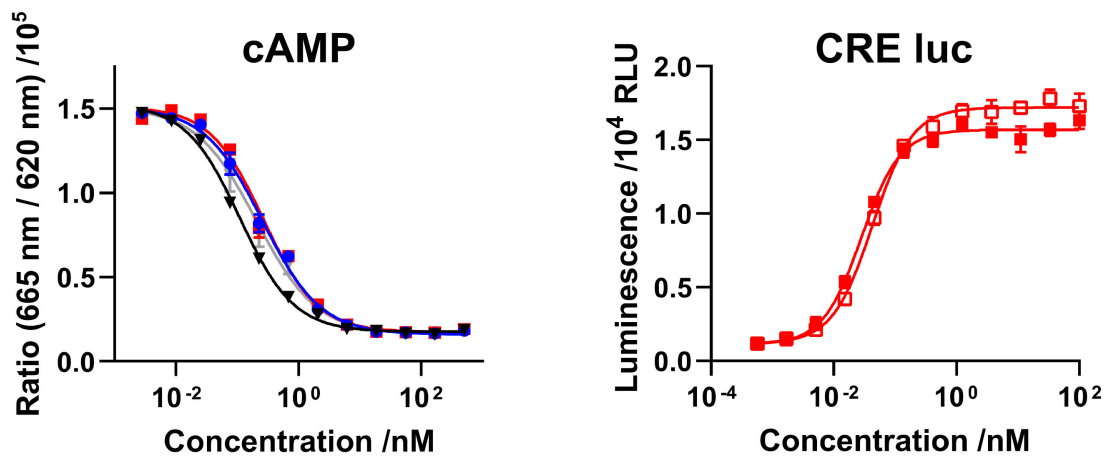

$$
\begin{array}{ll}
\rightarrow \text { Ex-4 } & \rightarrow \text { Ex-4[M14L, E17C, E24C] - S2 } \\
\rightarrow \text { Ex-4[E17C, E24C]-S2 } \rightarrow \text { Ex-4[M14L, E17C, E24C]-S2, recombinant }
\end{array}
$$

Figure 6. Dose-response curves for chemically synthesized and semisynthetic GLP-1R agonists in intracellular cAMP assay or CRE luciferase reporter assay (see Materials and Methods section, EC $_{50}$ values shown in Table 3).

Table 3. Activity of chemically-synthesized and recombinantly expressed (semisynthetic) GLP-1R agonist sequences, with/without M14L mutation, stapled with S2 (CRE luciferase reporter assay and intracellular cAMP assay, see Materials and Methods section).

\begin{tabular}{lcccc}
\hline \multirow{2}{*}{ Peptide } & \multirow{2}{*}{ Origin } & Staple & \multicolumn{2}{c}{ GLP-1R EC 5 /pM } \\
\cline { 3 - 5 } & & & CRE & cAMP \\
\hline Ex-4 & Synthetic & - & $37 \pm 3$ & $111 \pm 6$ \\
Ex-4[E17C, E24C] & Synthetic & S2 & - & $260 \pm 20$ \\
Ex-4[M14L, E17C, E24C] & Synthetic & S2 & $28 \pm 2$ & $270 \pm 30$ \\
Ex-4[M14L, E17C, E24C] & Recombinant & S2 & $43 \pm 2$ & - \\
\hline
\end{tabular}

The half-life of Ex-4[M14L, E17C, E24C]-S2 was evaluated in mouse, as carried out for the Met analog (Figure 7a). Male CD-1 mice $(\mathrm{n}=3)$ were administered peptide via either SC $(1 \mathrm{mg} / \mathrm{kg})$ or IV $(0.3 \mathrm{mg} / \mathrm{kg})$ route, and plasma samples were collected at $0.5,1,3,7,24,48$, and $72 \mathrm{~h}$ for SC and $5 \mathrm{~min}$ and 1, 3, 7, 24, 48, and $72 \mathrm{~h}$ for IV dosing. Peptide plasma concentrations were determined as previously carried out via CRE luc reporter assay. Pharmacokinetic parameters are given in Table 4. Ex-4[M14L, E17C, E24C]-S2 exhibits an IV half-life of over $6 \mathrm{~h}$ and up to $8 \mathrm{~h}$ via SC administration, which is comparable to that observed for Ex-4[E17C, E24C]-S2.

In order to demonstrate a blood glucose-lowering effect upon administration of Ex-4[M14L, E17C, E24C]-S2, we carried out an oral glucose tolerance test (OGTT) in C57BL/6 mice. Mice were challenged with $2 \mathrm{~g} / \mathrm{kg}$ oral glucose $1 \mathrm{~h}$ after dosing of either vehicle $(\mathrm{n}=4)$ or peptide. Significant glucose control was observed upon SC administration of Ex-4[M14L, E17C, E24C]-S2 $(0.05 \mathrm{mg} / \mathrm{kg}, \mathrm{n}=2)$, as shown in Figure $7 b, c$.

The promising data described demonstrate that both the staple modification and Met-to-Leu substitution do not adversely affect the in vivo pharmacokinetics or efficacy of our stapled long-acting Ex-4 peptide, demonstrating the potential for development of the new optimized lead Ex-4[M14L, E17C, E24C]-S2 as a once-weekly dosed GLP-1R agonist. 
(a)

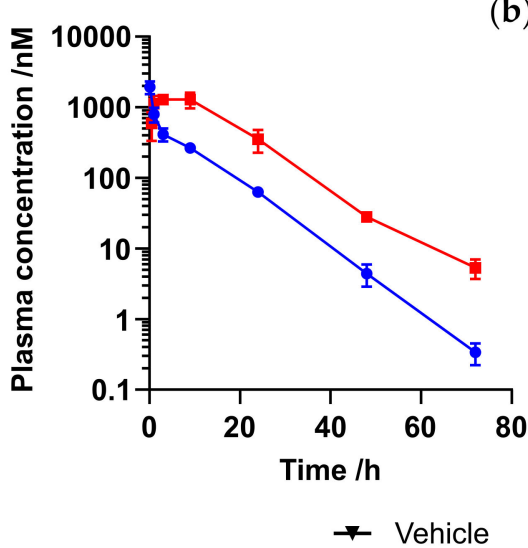

(b)

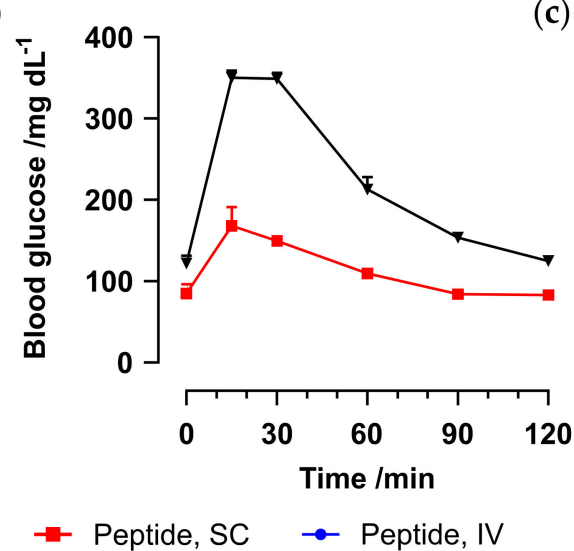

(c)

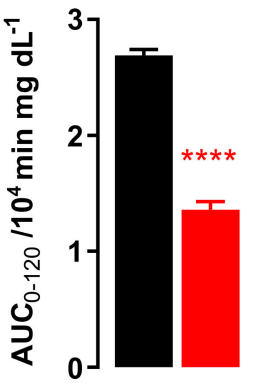

Figure 7. (a) Mouse pharmacokinetic data for Ex-4[M14L, E17C, E24C]-S2 administered via intravenous (IV) or subcutaneous (SC) injection to male CD-1 mice $(n=3)$, blood samples were collected between 0.5 and $48 \mathrm{~h}$ after dosing, and plasma concentration of the peptides was analyzed via CRE luc reporter functional assay, as detailed in the Materials and Methods section; (b) oral glucose tolerance test (OGTT) $1 \mathrm{~h}$ after administration of vehicle (phosphate-buffered saline, PBS, pH 8.2, black line) or Ex-4[M14L, E17C, E24C]-S2 $(0.05 \mathrm{mg} / \mathrm{kg}, \mathrm{SC}) ;{ }^{* * * *} p<0.0001$, relative to vehicle control; (c) refers to plasma glucose levels obtained by measuring the area under the curve (AUC).

Table 4. Mouse pharmacokinetic data for Ex-4[M14L, E17C, E24C]-S2.

\begin{tabular}{llcc}
\hline & Parameter & IV & SC \\
\hline Dose & $/ \mathrm{mg} \cdot \mathrm{kg}^{-1}$ & 0.3 & 1 \\
$\mathrm{~T}_{1 / 2}$ & $/ \mathrm{h}$ & $6.3 \pm 0.4$ & $8.0 \pm 0.3$ \\
$\mathrm{CL}$ & $/ \mathrm{mL} \cdot \mathrm{min}^{-1} \cdot \mathrm{kg}^{-1}$ & $0.14 \pm 0.01$ & $0.14 \pm 0.04$ \\
$\mathrm{~T}_{\max }$ & $/ \mathrm{h}$ & $0.08 \pm 0$ & $4 \pm 2$ \\
$\mathrm{C}_{\max }$ & $/ \mu \mathrm{g} \cdot \mathrm{mL}^{-1}$ & $10 \pm 2$ & $7 \pm 1$ \\
$\mathrm{AUC}_{\text {all }}$ & $/ \mathrm{h} \cdot \mu \mathrm{g} \cdot \mathrm{mL}^{-1}$ & $35 \pm 3$ & $120 \pm 30$ \\
$\mathrm{~V}_{\mathrm{ss}}$ & $/ \mathrm{L} \cdot \mathrm{kg}^{-1}$ & $0.077 \pm 0.005$ & $0.10 \pm 0.03$ \\
\hline
\end{tabular}

\section{Materials and Methods}

Unless otherwise noted, all reagents were purchased from commercial suppliers (MilliporeSigma, Merck KGaA, Darmstadt, Germany; Fisher Scientific, Waltham, MA, USA) and used without further purification. Chemically-synthesized peptides were purchased from Cellmano Biotech Limited (Hefei, China), InnoPep (San Diego, CA, USA), Shanghai Apeptide Co. (Shanghai, China), or Shanghai Dechi Biosciences Co. (Shanghai, China). Staples S1 and S2 were purchased from WuXi Apptec Co. (Shanghai, China) and synthesized as previously reported $[7,14]$. Semipreparative reversed-phase HPLC (RP-HPLC) was performed on an Agilent 1200 HPLC with a Phenomenex Luna column (C18, $100 \AA ̊$ pore size, $5 \mu \mathrm{m}$ particle size, $150 \times 21.2 \mathrm{~mm}$, flow: $20 \mathrm{~mL} / \mathrm{min})$ using A $\left(\mathrm{H}_{2} \mathrm{O}, 0.05 \%\right.$ TFA) and B (MeCN, 0.05\% TFA). High-resolution mass spectra (HRMS) were recorded on an Agilent 1200 Series Accurate Mass Time-of-Flight (TOF) with an Aeris Widepore column (Phenomenex, Torrance, CA, USA) (XB-C8, $3.6 \mu \mathrm{m}$ particle size, $150 \times 2.1 \mathrm{~mm}$, flow: $0.5 \mathrm{~mL} / \mathrm{min}$ ). Solvents: $\mathrm{A}-\mathrm{H}_{2} \mathrm{O}+0.1 \%$ formic acid, B-MeCN $+0.1 \%$ formic acid, gradient: $0-2 \min 5 \% \mathrm{~B}, 2-12 \min 5-60 \% \mathrm{~B}, 12-13 \min 60-80 \%$ B, 13-14 min 80-20\% B, 14-15 min 20-80\% B, 15-16 min 80-20\% B, 16-17 min 20-95\% B, 17-20 min $95 \% \mathrm{~B}$, and $20-21 \mathrm{~min} 95-5 \% \mathrm{~B}$. All animal care and experimental procedures were approved by the Institutional Animal Care and Use Committee (IACUC) of the California Institute for Biomedical Research (Calibr) and strictly followed the NIH guidelines for humane treatment of animals. 


\subsection{Recombinant Expression of Ex-4[M14L, E17C, E24C]}

Ex4[M14L, E17C, E24C] fused to N-terminal thioredoxin (Trx) and His 6 tags (MSDKIIHLTDD SFDTDVLKADGAILVDFWAEWCGPCKMIAPILDEIADEYQGKLTVAKLNIDQNPGTAPKYGIRGIPT LLLFKNGEVAATKVGALSKGQLKEFLDANLAGSGSGSMGSSHHHHHHSSGDDDDKHGEGTFTSDL SKQLEECAVRLFICWLKNGGPSSGAPPPS) was successfully cloned into a pET28a vector, with an enterokinase cleavage site (DDDDK) engineered between the His-tag and exenatide sequence. The fusion protein was recombinantly expressed in E. coli (BL21 AI) as the cytoplasmic, soluble fraction. For expression, an overnight culture in $10 \mathrm{~mL}$ of $\mathrm{LB} /$ kanamycin was diluted 1:100 in $1 \mathrm{~L}$ of $\mathrm{LB} / \mathrm{kanamycin}$ and cultured at $37^{\circ} \mathrm{C}$ until $\mathrm{OD}_{600}$ reached $0.8 .1 \mathrm{mM}$ IPTG and $0.2 \%$ arabinose was added to the culture, which was incubated at $37^{\circ} \mathrm{C}$ for $4 \mathrm{~h}$ and then centrifuged at $5000 \mathrm{rpm}$ for $20 \mathrm{~min}$. The pellet was dissolved in $100 \mathrm{mM}$ Tris (pH 8), $300 \mathrm{mM} \mathrm{NaCl}, 10 \mathrm{mM}$ imidazole, and $1 \mathrm{mM}$ PMSF, followed by lysis with a homogenizer at $18000 \mathrm{psi}$, three times. The lysate was then centrifuged at $10000 \mathrm{rpm}$ for $20 \mathrm{~min}$ at $4{ }^{\circ} \mathrm{C}$ to clarify the lysed cell suspension and the supernatant was incubated with prewashed Ni-NTA resin in $100 \mathrm{mM}$ Tris ( $\mathrm{pH}$ 8), $300 \mathrm{mM} \mathrm{NaCl}, 10 \mathrm{mM}$ imidazole, and $1 \mathrm{mM}$ PMSF, for $1 \mathrm{~h}$ at RT. The protein was eluted with $100 \mathrm{mM}$ Tris (pH 8), $300 \mathrm{mM} \mathrm{NaCl}$, and $200 \mathrm{mM}$ imidazole, to yield $\sim 30 \mathrm{mg} / \mathrm{L}$. The Trx tag was selectively cleaved by enterokinase $100 \mathrm{IU} / 5 \mathrm{mg}$ for $16 \mathrm{~h}$ at $\mathrm{RT}$ in $20 \mathrm{mM}$ Tris (pH 7.4), $50 \mathrm{mM} \mathrm{NaCl}$, and $2 \mathrm{mM} \mathrm{CaCl}_{2}$. After digestion, the solution was concentrated using an Amicon 10K MWCO filter, followed by RP-HPLC purification (30-50\% B over $40 \mathrm{~min}$ ), to yield $4 \mathrm{mg} / \mathrm{L}$ of peptide ( $86 \%$ purity by HPLC).

\subsection{Peptide Stapling}

DiCys-containing peptide was dissolved at a concentration of $2 \mathrm{mM}$ with $1.5 \mathrm{eq}$ of bromoacetyl staple in 1:3 $(v / v) \mathrm{MeCN} / 30 \mathrm{mM} \mathrm{NH}_{4} \mathrm{HCO}_{3}$ buffer ( $\mathrm{pH}$ 8.5). The $\mathrm{pH}$ of the reaction mixture was readjusted with ammonium hydroxide to correct the drop in $\mathrm{pH}$ caused by the peptide TFA counterion. More $\mathrm{MeCN}$ was added for particularly insoluble peptides. The reaction was stirred at RT for $2-4 \mathrm{~h}$ and monitored by LC-MS, before acidification to $\mathrm{pH} 5$ via dropwise addition of acetic acid. The resulting solution was lyophilized and purified by RP-HPLC ( $40-60 \%$ B over $40 \mathrm{~min})$ (12\% yield after purification, $96 \%$ final purity by HPLC).

\subsection{Intracellular cAMP Assay}

To measure peptide-induced GLP-1R-mediated stimulation of cyclic adenosine monophosphate (cAMP) production, a cAMP homogenous time resolved fluorescence (HTRF) assay was performed according to the manufacturer's instructions (cAMP-Gs Dynamic kit, Cisbio). Briefly, cAMP Hunter CHO cells expressing GLP-1R (DiscoveRx) were seeded overnight in white 384-well plates at 5000 cells per well in $20 \mu \mathrm{L}$ of $\mathrm{F} 12$ medium at $37{ }^{\circ} \mathrm{C}$ and $5 \% \mathrm{CO}_{2}$. The following day, the medium was removed and replaced with $20 \mu \mathrm{L}$ of Opti-MEM (Gibco) without FBS. Peptides (prepared as 5X solution in Opti-MEM) of different concentrations, and forskolin (a direct activator of adenylate cyclase enzyme, final concentration $10 \mu \mathrm{M}$ ), were added and incubated for $30 \mathrm{~min}$ at $37^{\circ} \mathrm{C}$. Detection reagent was added and further incubated for $60 \mathrm{~min}$ at room temperature, and read on a compatible HTRF reader (PHERAstar). Concentration-response curves were determined by nonlinear regression analysis using the Prism software (GraphPad Software Inc.).

\subsection{CRE Luciferase Reporter Assay}

HEK293 cells were infected with lentivirus encoding firefly luciferase gene under the control of cAMP responsive element (CRE) promoter (Qiagen, Venlo, Netherlands) and then were selected using $1 \mu \mathrm{g} / \mathrm{mL}$ puromycin (Life Technologies, Carlsbad, CA, USA) for 1 week. The surviving cells (referred to as CRE-HEK293) were expanded and then transfected with a G418 selective mammalian expression plasmid encoding human GLP-1R. The GLP-1R plasmid was transfected into CRE-HEK293 cells using Lipofectamine 2000 and selected with $400 \mu \mathrm{g} / \mathrm{mL}$ geneticin (Life Technologies, Carlsbad, CA, USA). 
A single colony stable cell line overexpressing both CRE-luciferase and GLP-1R (HEK293-GLP-1R-CRE) was then established for the in vitro activity assay. HEK293-GLP-1R-CRE cells were seeded in 384-well plates at a density of 5000 cells per well and cultured for $18 \mathrm{~h}$ in DMEM with $10 \%$ FBS at $37{ }^{\circ} \mathrm{C}$ and $5 \% \mathrm{CO}_{2}$. Cells were treated with peptides for $24 \mathrm{~h}$, and receptor activation was reported by luminescence intensities, using One-Glo (Promega, WI) luciferase reagent as per the manufacturer's instructions. The $\mathrm{EC}_{50}$ value for each peptide was determined using GraphPad Prism 6 software (GraphPad, San Diego, CA, USA).

\subsection{In Vivo Pharmacokinetics Studies}

All animal care and experimental procedures were approved by the Institutional Animal Care and Use Committee (IACUC, protocol number CR6-002) of the California Institute for Biomedical Research (Calibr) and strictly followed the NIH guidelines for humane treatment of animals. Male CD-1 mice (age 10 weeks, $\mathrm{n}=4$ per group) were administrated with $100 \mu \mathrm{L}$ of each peptide in phosphate buffered saline by SC or IV route. Blood $(50 \mu \mathrm{L})$ was extracted into heparin tubes and centrifuged at 10,000 rpm for $5 \mathrm{~min}$. Collection time points were as follows, SC: 0.25 or $0.5,1,3,7,10,24,48$, and 72 h; IV: $5 \mathrm{~min}$ and $1,3,7,10,24,48$, and $72 \mathrm{~h}$. The resulting supernatant plasma were then stored at $-80^{\circ} \mathrm{C}$. The concentrations of peptides in plasma at each time point were determined by cell-based CRE luciferase reporter assay as described. Peptide concentrations in plasma were obtained and plotted against time points to obtain in vivo half-life of each peptide, using WinNonLin Phoenix software (Pharsight Corp, St. Louis, MO, USA).

\subsection{Diet-Induced Obesity (DIO) Mouse Body Weight Model}

Diet-induced obesity (DIO) model male mice (age 18 weeks from Taconic Biosciences, La Jolla, CA, USA) maintained on high fat diet (D12492, 60\% fat diet) for 12 weeks were administered peptide by daily subcutaneous injection for up to 12 days $(n=6$, group housed two per cage, regular light cycle). The average body weight at the beginning of the experiment was $50 \mathrm{~g}$. Mouse body weight and food intake was measured daily from day 0 onwards. Mice were fasted overnight prior to the oral glucose tolerance test (OGTT) on day 1, and then dosed with peptide. After $6 \mathrm{~h}, 1 \mathrm{~g}$ of glucose solution per $\mathrm{kg}$ body weight was administered orally, and mouse tail blood glucose levels were measured before ( $0 \mathrm{~min})$ and after glucose challenge for $2 \mathrm{~h}$. The terminal bleed was collected to evaluate metabolic profile (serum triglycerides and total cholesterol). The data were compared using the unpaired Student's $t$-test. Where appropriate, data were compared using repeated measures or one-way analysis of variance, followed by the Student-Newman-Keuls post-hoc test.

\subsection{Wild Type in Vivo Oral Glucose Tolerance Test (OGTT)}

C57BL/6 male mice (age 10 weeks) were fasted overnight $(\sim 16 \mathrm{~h})$ and treated with vehicle $(\mathrm{n}=4)$ or peptide via SC injection $(n=2) 1 \mathrm{~h}$ prior to oral glucose tolerance test (OGTT). After $1 \mathrm{~h}, 2 \mathrm{~g}$ of glucose solution per $\mathrm{kg}$ body weight was administered orally, and mouse tail blood glucose levels were measured before $\left(\mathrm{T}_{0}, 0 \mathrm{~min}\right)$ and after glucose challenge for $2 \mathrm{~h}$. The data were compared using the unpaired Student's $t$-test. Where appropriate, data were compared using repeated measures or one-way analysis of variance, followed by the Student-Newman-Keuls post-hoc test.

\section{Conclusions}

We have demonstrated a robust semisynthetic protocol for the production of a long-acting exenatide analog, Ex-4[M14L, E17C, E24C]-S2, involving recombinant expression of the linear precursor peptide followed by stapling using Cys-reactive chemistry. Furthermore, the methionine residue susceptible to oxidation in the native exenatide sequence was replaced by leucine, and the newly developed symmetric staple $\mathbf{S} 2$ was used in order to circumvent regioisomer formation occuring during synthesis of the first-generation long-acting S1-stapled exenatide previously reported. All analogs-including the semisynthetic material—retained comparable in vitro GLP-1R activity in cell-based assays. The staple 
modification was shown to cause no adverse effect on half-life in mouse, and full validation of in vivo efficacy for the $\mathbf{S} \mathbf{2}$ analog was carried out in a diet-induced obesity mouse model. An in vivo half-life of $8 \mathrm{~h}$ was established for Ex-4[M14L, E17C, E24C]-S2. SC efficacy was also demonstrated for this analog in an in vivo glucose control study. The expression protocol for the long-acting stapled exenatide analogs described, which contain only proteinogenic amino acids in the peptide backbone, will enable low-cost production at scales not possible using chemical synthesis alone. Given the impressive PK and efficacy demonstrated here, these results pave the way for development of Ex-4[M14L, E17C, E24C]-S2 as a GLP-1R agonist therapeutic.

\section{Patents}

The lead molecules described and their potential application are covered in U.S. Provisional Patent Application No. 62/994,791, which has been filed.

Author Contributions: Conceptualization, W.S.; methodology, H.S., L.L., S.L., D.H., and Z.A.; validation, C.L., H.Z. and Z.Z.; formal analysis, C.L., D.H., H.Z., and Z.Z.; investigation, S.L., H.S., C.L., L.L., D.H., H.Z., and Z.Z.; writing-original draft preparation, S.L.; writing-review and editing, S.L., Z.A., and W.S.; visualization, S.L.; supervision, W.S. and V.T.B.N.-T.; project administration, W.S. and V.T.B.N.-T. All authors have read and agreed to the published version of the manuscript.

Funding: This research received no external funding.

Acknowledgments: We would like to thank Victor Chi for technical support.

Conflicts of Interest: The authors declare no conflict of interest.

\section{References}

1. Holst, J.J.; Gromada, J. Role of incretin hormones in the regulation of insulin secretion in diabetic and nondiabetic humans. Am. J. Physiol. Endocrinol. Metab. 2004, 287, E199-E206. [CrossRef]

2. Meier, J.J. GLP-1 receptor agonists for individualized treatment of type 2 diabetes mellitus. Nat. Rev. Endocrinol. 2012, 8, 728. [CrossRef]

3. Lear, S.; Amso, Z.; Shen, W. Engineering PEG-fatty acid stapled, long-acting peptide agonists for G protein-coupled receptors. In Methods in Enzymology; Shukla, A.K., Ed.; Academic Press: Cambridge, MA, USA, 2019; Volume 622, pp. 183-200. [CrossRef]

4. Mehta, A.; Marso, S.P.; Neeland, I.J. Liraglutide for weight management: A critical review of the evidence. Obes. Sci. Pract. 2017, 3, 3-14. [CrossRef]

5. Armstrong, M.J.; Gaunt, P.; Aithal, G.P.; Barton, D.; Hull, D.; Parker, R.; Hazlehurst, J.M.; Guo, K.; Abouda, G.; Aldersley, M.A.; et al. Liraglutide safety and efficacy in patients with non-alcoholic steatohepatitis (LEAN): A multicentre, double-blind, randomised, placebo-controlled phase 2 study. Lancet 2016, 387, 679-690. [CrossRef]

6. Newsome, P.; Francque, S.; Harrison, S.; Ratziu, V.; Van Gaal, L.; Calanna, S.; Hansen, M.; Linder, M.; Sanyal, A. Effect of semaglutide on liver enzymes and markers of inflammation in subjects with type 2 diabetes and/or obesity. Aliment. Pharmacol. Ther. 2019, 50, 193-203. [CrossRef] [PubMed]

7. Yang, P.Y.; Zou, H.; Chao, E.; Sherwood, L.; Nunez, V.; Keeney, M.; Ghartey-Tagoe, E.; Ding, Z.; Quirino, H.; Luo, X.; et al. Engineering a long-acting, potent GLP-1 analog for microstructure-based transdermal delivery. Proc. Natl. Acad. Sci. USA 2016, 113, 4140-4145. [CrossRef]

8. Lau, J.; Bloch, P.; Schaffer, L.; Pettersson, I.; Spetzler, J.; Kofoed, J.; Madsen, K.; Knudsen, L.B.; McGuire, J.; Steensgaard, D.B.; et al. Discovery of the once-weekly glucagon-like peptide-1 (GLP-1) analogue semaglutide. J. Med. Chem. 2015, 58, 7370-7380. [CrossRef] [PubMed]

9. Agersø, H.; Jensen, L.B.; Elbrønd, B.; Rolan, P.; Zdravkovic, M. The pharmacokinetics, pharmacodynamics, safety and tolerability of NN2211, a new long-acting GLP-1 derivative, in healthy men. Diabetologia 2002, 45, 195-202. [CrossRef] [PubMed]

10. Havelund, S.; Plum, A.; Ribel, U.; Jonassen, I.; Vølund, A.; Markussen, J.; Kurtzhals, P. The mechanism of protraction of insulin detemir, a long-acting, acylated analog of human insulin. Pharm. Res. 2004, 21, 1498-1504. [CrossRef] 
11. Drab, S.R.; Philis-Tsimikas, A. A new option for glycemic control: Insulin degludec, a new-generation basal insulin with an ultralong duration of action. Pharmacotherapy 2014, 34, 291-302. [CrossRef] [PubMed]

12. Verdine, G.L.; Hilinski, G.J. Stapled peptides for intracellular drug targets. In Methods in Enzymology; Wittrup, K.D., Verdine, G.L., Eds.; Academic Press: Cambridge, MA, USA, 2012; Volume 503, pp. 3-33. [CrossRef]

13. White, A.M.; Craik, D.J. Discovery and optimization of peptide macrocycles. Expert. Opin. Drug. Dis. 2016, 11, 1151-1163. [CrossRef] [PubMed]

14. Yang, P.Y.; Zou, H.; Amso, Z.; Lee, C.; Huang, D.; Woods, A.K.; Nguyen-Tran, V.T.B.; Schultz, P.G.; Shen, W. New generation oxyntomodulin peptides with improved pharmacokinetic profiles exhibit weight reducing and anti-steatotic properties in mice. Bioconjugate Chem. 2020, 31, 1167-1176. [CrossRef] [PubMed]

15. Levy, O.E.; Jodka, C.M.; Ren, S.S.; Mamedova, L.; Sharma, A.; Samant, M.; D’Souza, L.J.; Soares, C.J.; Yuskin, D.R.; Jin, L.J.; et al. Novel exenatide analogs with peptidic albumin binding domains: Potent anti-diabetic agents with extended duration of action. PLoS ONE 2014, 9, e87704. [CrossRef] [PubMed]

16. Hargrove, D.M.; Kendall, E.S.; Reynolds, J.M.; Lwin, A.N.; Herich, J.P.; Smith, P.A.; Gedulin, B.R.; Flanagan, S.D.; Jodka, C.M.; Hoyt, J.A.; et al. Biological activity of AC3174, a peptide analog of exendin-4. Regul. Peptides 2007, 141, 113-119. [CrossRef] [PubMed]

17. McNiff, M.L.; Haynes, E.P.; Dixit, N.; Gao, F.P.; Laurence, J.S. Thioredoxin fusion construct enables high-yield production of soluble, active matrix metalloproteinase-8 (MMP-8) in Escherichia coli. Protein Expres. Purif. 2016, 122, 64-71. [CrossRef] [PubMed]

18. LaVallie, E.R.; DiBlasio-Smith, E.A.; Collins-Racie, L.A.; Lu, Z.; McCoy, J.M. Thioredoxin and related proteins as multifunctional fusion tags for soluble expression in E. coli. In E. coli Gene Expression Protocols; Vaillancourt, P.E., Ed.; Humana Press Inc.: Totowa, NJ, USA, 2003; pp. 119-140. [CrossRef]

Sample Availability: Samples of the compounds may be obtained from the authors with the appropriate Material Transfer Agreement in place.

(C) 2020 by the authors. Licensee MDPI, Basel, Switzerland. This article is an open access article distributed under the terms and conditions of the Creative Commons Attribution (CC BY) license (http://creativecommons.org/licenses/by/4.0/). 